\title{
High-hydrostatic-pressure optical chamber system for cultivation and microscopic observation of deep-sea organisms
}

\author{
Chengman Bao', Yun Gai ${ }^{2}$, Kaikai Lou ${ }^{2}$, Chunyue Jiang ${ }^{3}$, Shuming $\mathrm{Ye}^{2, *}$ \\ ${ }^{1}$ College of Life Sciences, Zhejiang University, Hangzhou 310058, PR China \\ ${ }^{2}$ College of Biomedical Engineering and Instrument Science, Zhejiang University, Hangzhou 310027, PR China \\ ${ }^{3}$ College of Chemical Engineering and Materials Science, Zhejiang University of Technology, Hangzhou 310014, PR China
}

\begin{abstract}
We developed and tested a high-pressure optical chamber system for cultivation and microscopic observation of deep-sea organisms. The system is composed of an optical chamber, a highpressure pump, a pressure sensor and a microscope. The chamber has an observation cavity, 2 cultivation cavities and 2 sapphire windows. The pump is employed for perfusion of culture medium and for increasing the pressure. The pressure sensor monitors the pressure in the chamber. The microscope is used for observing samples through the sapphire windows. In the future, the optical chamber system could be used alone for short-term research or be connected to a large high-pressure vessel to create a flow-through system for long-term research. Using the system, the swimming activity of Bosmina longirostris (Branchiopoda: Cladocera) was observed at different pressures. Swimming activity increased with increasing compression up to $30 \mathrm{MPa}$. During decompression, this activity reappeared when pressure decreased to $45 \mathrm{MPa}$ and increased with further decreasing pressure.
\end{abstract}

KEY WORDS: Optical chamber system $\cdot$ Real-time $\cdot$ Microscopic observation $\cdot$ Plankton Resale or republication not permitted without written consent of the publisher

\section{INTRODUCTION}

Many organisms live in the deep sea at high pressure and low temperatures. Since large numbers of biological communities were first discovered near hydrothermal vents (Lonsdale 1977), much interest has been focused on the effects of hydrostatic pressure on a variety of deep-sea organisms (Sakiyama \& Ohwada 1998, Kaye \& Baross 2004, Partridge et al. 2006, Campanaro et al. 2008). Many studies have shown that organisms retrieved from depths of 2000 to $3000 \mathrm{~m}$ or more do not survive under normal pressure (Gross \& Jaenicke 1994, Pradillon et al. 2004, Pradillon \& Gaill 2007). The effect of hydrostatic pressure on non-deep-sea organisms has been examined as well (Castillo et al. 2004, Black et al. 2005, Abe 2007, Horikawa et al. 2009).

In previous studies of biological systems, most experiments were based on the examination of the effect of pressure treatment by comparing states before and after the treatment. However, the lack of real-time microscopic observations of organisms, such as meiofauna, greatly weakens the conclusions of pressure effects. Many apparatuses have been designed for cultivation and real-time observation of organisms under high hydrostatic pressure (Yancey 2009). The hydrostatic pressure of these apparatuses ranges from 0.1 to $300 \mathrm{~atm}$ (Fraser \& Macdonald 1994, Marsh et al. 2001, Fraser \& Shelmerdine 2002, Pradillon et al. 2004, Shillito et al. 2004). Some apparatuses have windows of sapphire or Pyrex glass for real-time observation (Gregg et al. 1994, Grasset 2001, Koyama et al. 2001, Raber et al. 2006). However, these apparatuses have some drawbacks (Frey et al. 2006, Oger et al. 2006): (1) The sample volume is small and excludes some multicellular organisms; (2) Long-term real-time microscopic observations are not feasible; (3) The pressure is not high enough for deep-sea (e.g. $6000 \mathrm{~m}$ depth) organisms; (4) Pressure chambers are made of stainless steel, which may influence the organisms and can be damaged by seawater. 
To overcome these drawbacks, we developed a high-pressure optical chamber system specifically used for cultivation and microscopic observation of organisms ranging from 100 to $1000 \mu \mathrm{m}$ in size. The high-pressure chamber is made of titanium, which has been proven to be an excellent biocompatible material and can be used under high pressure up to $60 \mathrm{MPa}$ (6000 $\mathrm{m}$ depth in the deep sea). The chamber can either be used alone for short-term research or as part of a flow-through system by connection with a large vessel. A flow-through system could maintain water chemistry conditions in the pressure chamber for longterm observation without decreasing the pressure. We examined the stability of the pressure chamber system and successfully made real-time observations of plankton under different pressures.

\section{MATERIALS AND METHODS}

Optical chamber system. The highhydrostatic-pressure optical chamber system is mainly composed of an optical pressure chamber, a microscope, a pressure pump and a pressure sensor. The temperature is controlled by a water bath.

High-hydrostatic-pressure optical chamber: The optical chamber (Fig. 1) is made of titanium, an excellent material for highpressure research. The chamber is in the form of a rectangular box $(180 \times 44 \times$ $38 \mathrm{~mm})$, which has an observation cavity and 2 cultivation cavities. The maximum pressure in the chamber is $60 \mathrm{MPa}$.

The observation cavity (Fig. 2a) is $13 \mathrm{~mm}$ in diameter and provides 2 opposite optical windows for real-time microscopic observation. The optical window (Fig. 2b) is made of sapphire, $16 \mathrm{~mm}$ in diameter and $8 \mathrm{~mm}$ in thickness. It provides clear images with common microscopes and excellent biocompatibility. A fluorine rubber O-ring (16 $\mathrm{mm}$ diameter, $1.8 \mathrm{~mm}$ thick) is used to seal the window. The sapphire window is tightened by a compression cover, which has coned holes for microscopic observation. The 2 cultivation cavities, both $18 \mathrm{~mm}$ in diameter and $72 \mathrm{~mm}$ in length, are located at the 2 sides of the observation cavity. These cavities are connected to the observation cavity by channels of $3 \mathrm{~mm}$ in diameter and $6 \mathrm{~mm}$ in length.

The chamber has 2 pipe connections. For short-term observation, samples are injected into the chamber directly and cultivated for several days. In this case, only one pipe connection is used. For long-term observation, the chamber is connected to a large high-pressure vessel to built up a real-time flowing observation system. In this case, both pipe connections are used, one for inflow and the other for outflow. A net is used to prevent organisms from being flushed from the system during circulation.

Microscope and pressure pump: The pressure chamber is compatibe with a variety of microscopes by using objective lenses with long working distance. It is also feasible to use 2 kinds of pump for altering pressure: a hand pump for fast alteration and a reciprocating a

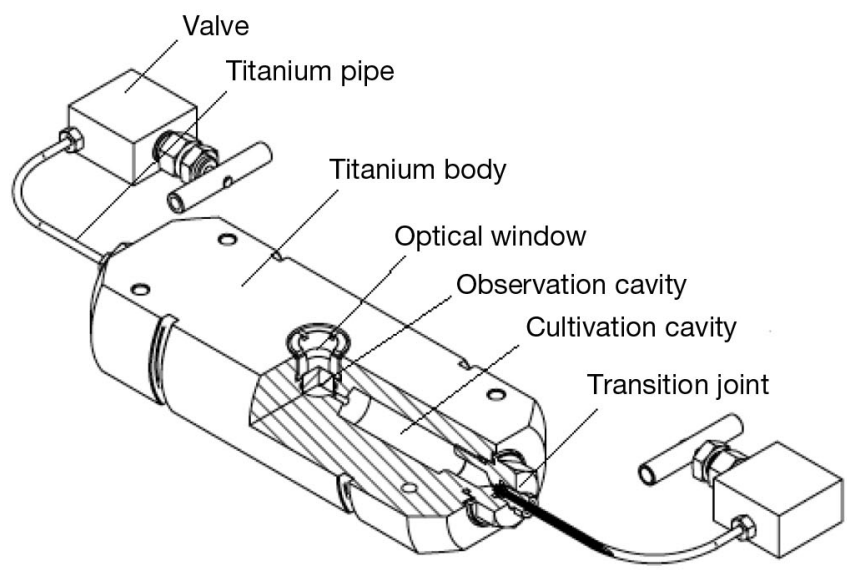

b
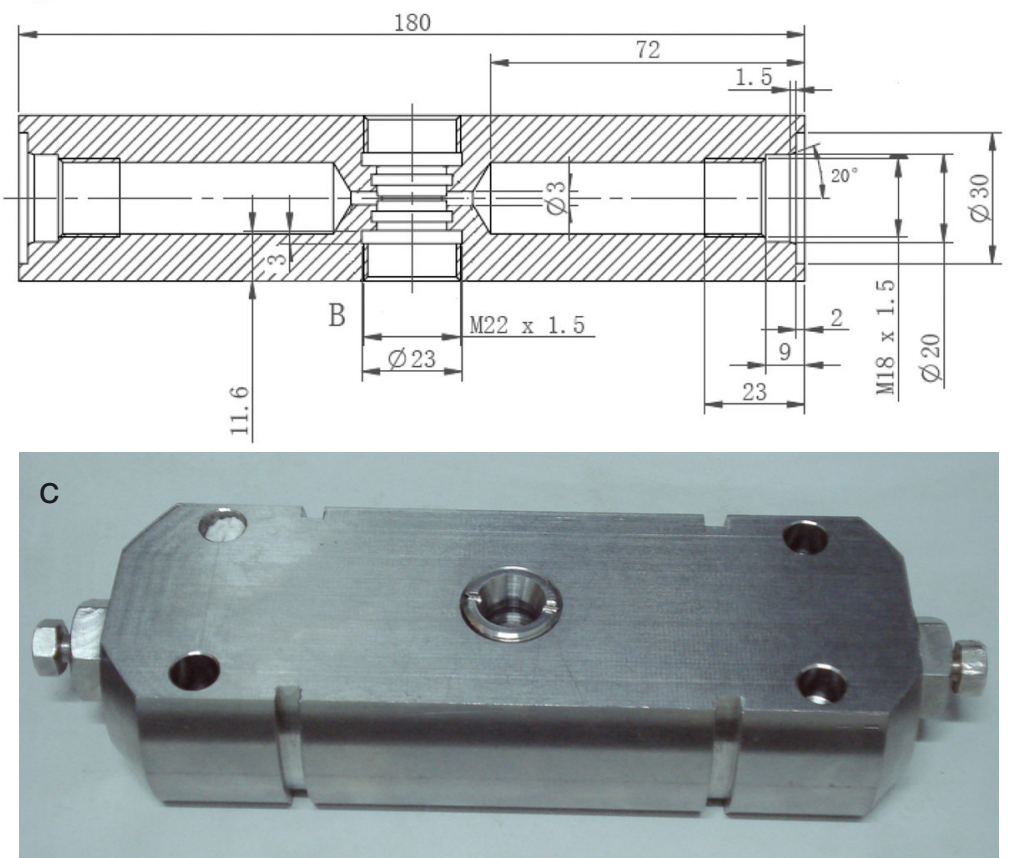

Fig. 1. (a) Schematic, (b) scale-drawing and (unit: $\mathrm{mm}$ ) (c) photograph of the high-hydrostatic-pressure optical chamber, which includes an observation cavity, 2 cultivation cavities and 2 sapphire windows 


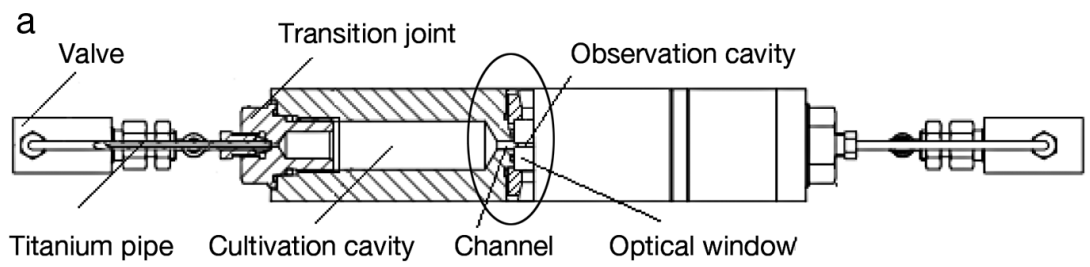

Fig. 2. (a) A longitudinal section of the high-hydrostatic-pressure optical chamber and (b) a closeup of the optical window which is circled in Fig. 2a

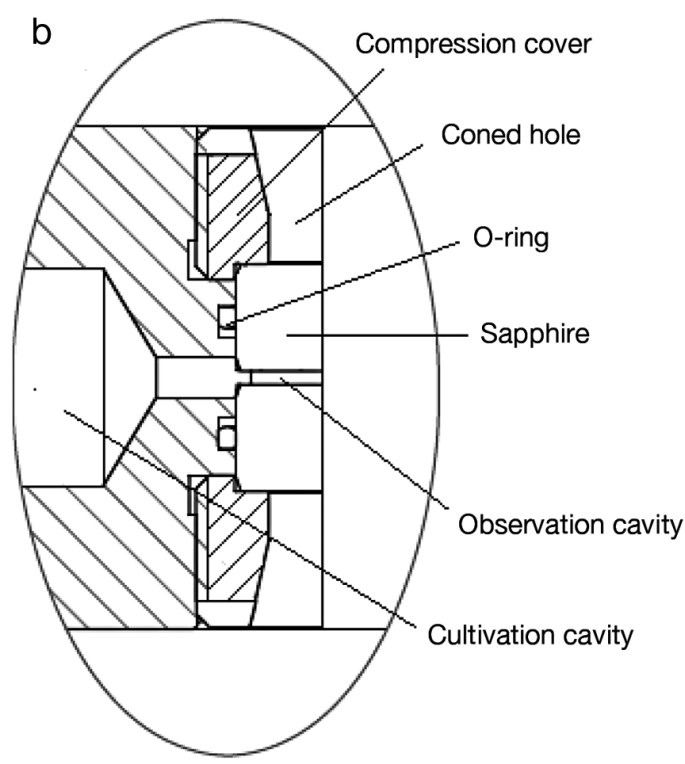

pump for slow alteration. The pressure in the chamber is monitored by a pressure sensor.

Study organisms. Cyclops vicinus (Cyclopoida: Crustacea) and Bosmina longirostris (Branchiopoda: Cladocera) were collected from a shallow freshwater pond and then transferred to an aquarium at room temperature. They were observed closely and found to be swimming very actively.

The organisms were observed with a long distance microscope (XTB-01) and the images were recorded via a CCD camera (Sony DSC-W50). Pressure was increased by a hand pump (JB-80) and monitored by a pressure sensor (pressure up to $80 \mathrm{MPa}$ ).

Validation experiments and Bosmina observations. Two types of validation experiments were performed to examine the pressure stability of the pressure chamber. In the first (Validation Expt 1), pressure was increased to $60 \mathrm{MPa}$ at different compression rates $\left(1,2,5\right.$ and $\left.10 \mathrm{MPa} \mathrm{min}^{-1}\right)$ and maintained for $2 \mathrm{~h}$. In the second (Validation Expt 2), pressure was increased to either $10,20,30,40,50$ or $60 \mathrm{MPa}$ at the rate of $1 \mathrm{MPa} \mathrm{min}^{-1}$ and maintained for $2 \mathrm{~h}$. To examine the imaging performance of the system, pictures of Cyclops vicinus in the pressure chamber were taken with the camera mounted on the microscope. These were compared with images of the copepod on a common glass slide.
Bosmina longirostris were observed in real-time under different pressures. Several B. longirostris were introduced into the chamber. The pressure was increased at a rate of $1 \mathrm{MPa} \mathrm{min}^{-1}$. When the pressure was $0.2 \mathrm{MPa}$, compression was stopped for several minutes. Then the compression was continued and stopped every $5 \mathrm{MPa}$ for several minutes until $60 \mathrm{MPa}$ was reached. The reverse process was carried out during decompression. As the experiments lasted only several hours, only clean pond water was used, without any additional nutrition or aeration. The Bosmina trials and the stability experiments were repeated twice (3 replicates).

\section{RESULTS}

\section{Validation experiments of the high-pressure chamber}

In Validation Expt 1 (pressure stability at $60 \mathrm{MPa}$ using different compression rates), fluctuations of pressures occurred mainly in the first $30 \mathrm{~min}$ once maximum pressure was reached, and the maximal fluctuation was 2.9 MPa (Fig. 3).

In Validation Expt 2 (pressure stability at different target pressures using a compression rate of $1 \mathrm{MPa}$ $\mathrm{min}^{-1}$ ), the ratios (P1:P0; $\mathrm{P} 0$ represents the target pressure and P1 represents pressure after $2 \mathrm{~h}$ ) were between 0.95 and 0.96 , indicating that once target pressures were reached, the pressures were stable during the $2 \mathrm{~h}$ observation period (Fig. 4).

The pictures taken of Cyclops vicinus in the pressure chamber were clear enough to observe activity in the samples, though darker and slightly blurred compared to photographs of $C$. vicinus on a common glass slide (Fig. 5).

\section{Real-time observation of the behavior of Bosmina longirostris at different pressures}

Before compression, the organisms were distributed along the observation cavity and displayed slight swimming activity. During the course of compression to $0.2 \mathrm{MPa}$, there was an immediate and distinct increase in swimming activity. When the pressure was stable at $0.2 \mathrm{MPa}$, the swimming activity declined to a level lower than that before the previous stable pressure. This 


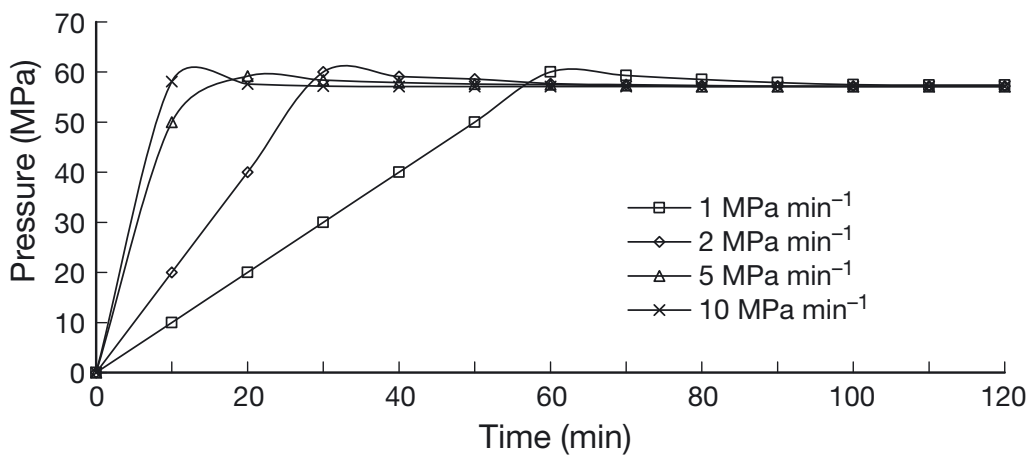

Fig. 3. Pressure fluctuations during compression from 0 to $60 \mathrm{MPa}$ at different compression rates and while maintaining maximum pressure (60 $\mathrm{MPa})$ for $2 \mathrm{~h}$ (Validation Expt 1)

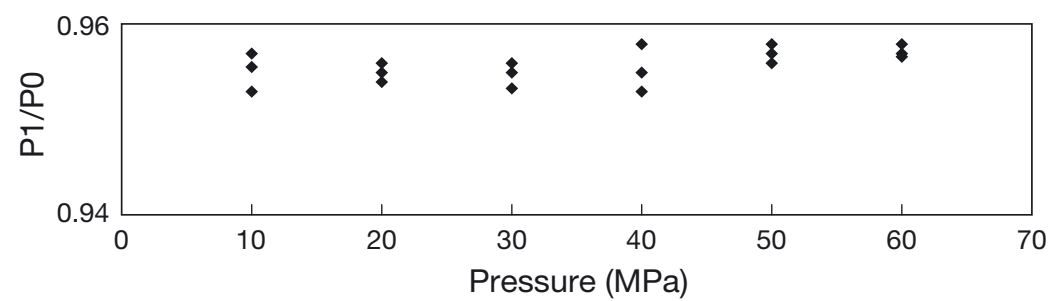

Fig. 4. Pressure fluctuations at different target pressures maintained for $2 \mathrm{~h}$ (Validation Expt 2). Fluctuations are expressed by the ratio P1:P0 where pressure after $2 \mathrm{~h}(\mathrm{P} 1)$ is divided by the target pressure (P0). The compression rate was $1 \mathrm{MPa} \mathrm{min}^{-1}$ phenomenon appeared repeatedly until $30 \mathrm{MPa}$. When pressure was between 30 and $45 \mathrm{MPa}$, there was no swimming activity except for leg vibrations. When the pressure was above $45 \mathrm{MPa}$, even the leg vibration stopped.

During the course of decompression, swimming activity occurred again at $45 \mathrm{MPa}$ and increased slowly as the pressure decreased below $45 \mathrm{MPa}$. This activity indicated that Bosmina longirostris survived exposure to high pressure of up to $60 \mathrm{MPa}_{\text {, }}$. These results are similar to earlier reports (Forward \& Wellins 1989, Forward 1990), but the real-time observation of $B$. longirostris under such high pressure has not been studied before.

\section{DISCUSSION}

In our experiments, a hand pump was used to increase pressure, as reported in other studies (Ross \& Quetin 1985, Pradillon et al. 2004), but this method exposes
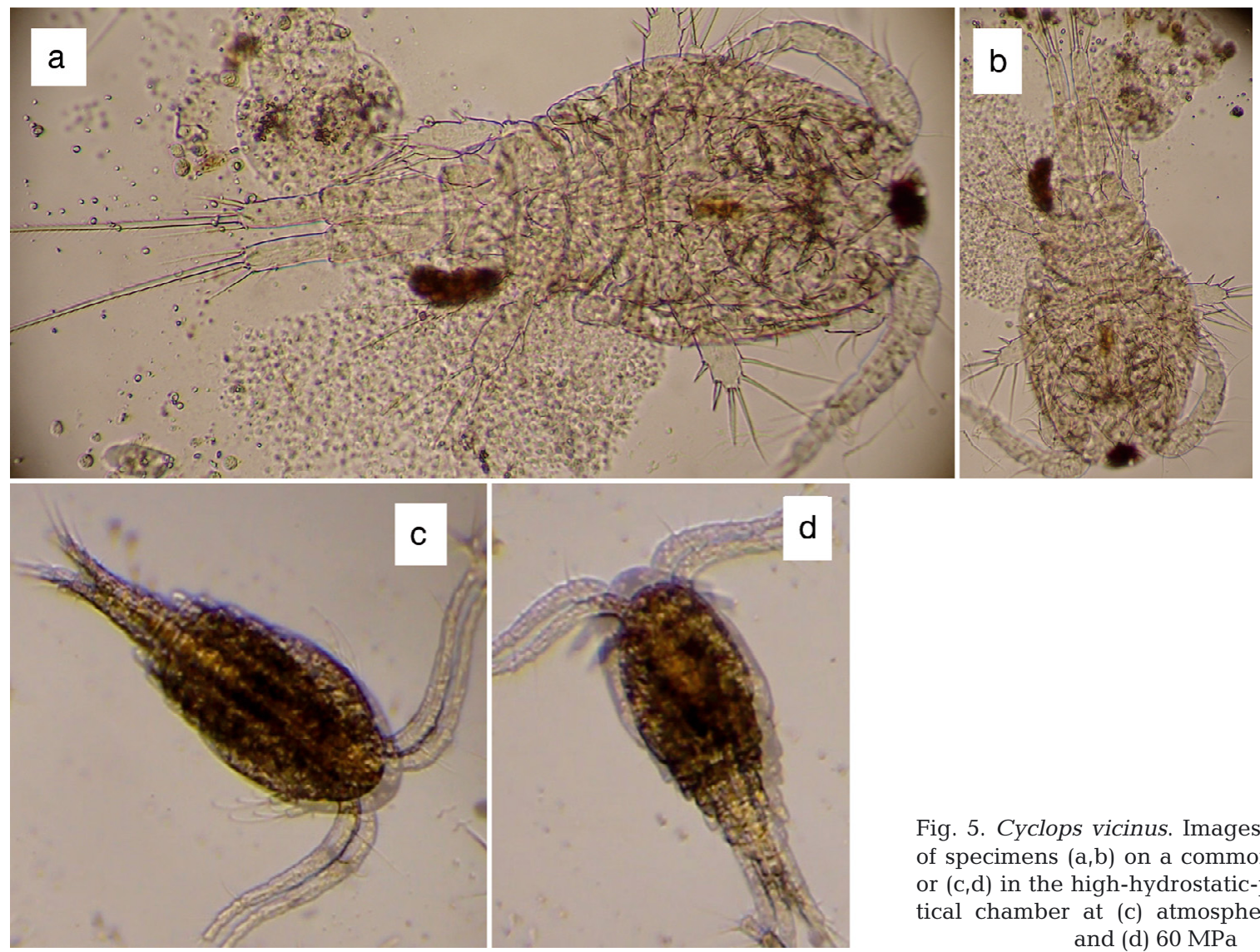

Fig. 5. Cyclops vicinus. Images were taken of specimens $(a, b)$ on a common glass slide or $(\mathrm{c}, \mathrm{d})$ in the high-hydrostatic-pressure optical chamber at (c) atmospheric pressure and (d) $60 \mathrm{MPa}$ 
organisms to abruptly increasing pressure, which may destroy the structure or change the characteristics of samples. Therefore, some researchers propose a reciprocating pump instead (Yoshiki et al. 2006). The reciprocating pump compresses the medium smoothly at a constant flow rate and maintains pressure more accurately in the chamber. We made a tie-in for the purpose of connecting a reciprocating pump. This improves the applicability of the high-pressure optical system (Bao et al. 2010).

Many zooplankton live throughout the water column and are exposed to a range of hydrostatic pressures in their lifetime. Bosmina longirostris belongs to the Branchiopoda, an important component of planktonic crustaceans. Many researchers have investigated the effects of hydrostatic pressure on the behavior of zooplankton (Childress \& Thuesen 1993, Bailey et al. 1994, Yoshiki et al. 2006, Yoshiki et al. 2008), but there is no direct evidence of the effects of extra-high pressure on the behavior of freshwater planktonic crustaceans. The high-hydrostatic-pressure optical chamber system allowed real-time observation and provided direct observations of biology under high pressure in our study of the behavior of Bosmina longirostris under different pressures.

In these experiments, we found that the highhydrostatic-pressure optical chamber offered slightly darker and more blurred images compared to photographing the organism on a glass slide through a microscope. This might be caused by the intensity of light in the chamber and the thickness of the observation window. It could be improved by enhancing the light intensity or using a fluorescence microscope.

\section{CONCLUSIONS}

The high-hydrostatic-pressure chamber system was specifically used for microscopic observation. The chamber system provided a means of microscopic observation of organisms under extreme high pressure of up to $60 \mathrm{MPa}$. The results showed that the pressure chamber system was stable for real-time observation under high pressure. The chamber could be used conveniently with different microscopes. It also provides video and still images if a camera is installed. Using the system, Bosmina longirostris was directly observed under high pressures.

Acknowledgements. We thank JCh. Luo, X. Wang and a laboratory assistant for their technical assistance and helpful advice. This work was supported by the National High-Tech Research and Development Plan of China (No. 2007AA 091902 No. 2007AA09Z210) and the National Natural Science Foundation of China (No. 40676059 No. 40927001).

\section{LITERATURE CITED}

Abe F (2007) Exploration of the effects of high hydrostatic pressure on microbial growth, physiology and survival: perspectives from piezophysiology. Biosci Biotechnol Biochem 71:2347-2357

> Bailey TG, Torres JJ, Youngbluth MJ, Qwen GP (1994) Effect of decompression on mesopelagic gelatinous zooplankton: a comparison of in situ and shipboard measurements of metabolism. Mar Ecol Prog Ser 113:13-27

Bao ChM, Ye ShM, Lou KK, Jiang ChY (2010) High-pressure optical cell system for online luminescence spectrum research. High Press Res 30:190-197

> Black EP, Kelly AL, Fitzgerald GF (2005) The combined effect of high pressure and nisin on inactivation of microorganisms in milk. Innov Food Sci Emerg Technol 6:286-292

Campanaro S, Treu L, Valle G (2008) Protein evolution in deep sea bacteria: an analysis of amino acids substitution rates. BMC Evol Biol 8:313

Castillo A. LA, Meszaros L, Kiss IF (2004) Effect of high hydrostatic pressure and nisin on micro-organisms in minced meats. Acta Aliment Hung 33:183-190

Childress JJ, Thuesen EV (1993) Effects of hydrostatic pressure on metabolic rates of six species of deep-sea gelatinous zooplankton. Limnol Oceanogr 38:665-670

Fraser PJ, Macdonald AG (1994) Crab hydrostatic pressure sensors. Nature 371:383-384

Fraser PJ, Shelmerdine RL (2002) Dogfish hair cells sense hydrostatic pressure. Nature 415:495-496

> Frey B, Hartmann M, Herrmann M, Meyer-Pittroff R, Sommer K, Bluemelhuber G (2006) Microscopy under pressure: an optical chamber system for fluorescence microscopic analysis of living cells under high hydrostatic pressure. Microsc Res Tech 69:65-72

Forward RB Jr (1990) Responses of crustacean larvae to hydrostatic pressure: behavioral basis of high barokinesis. Mar Freshwat Behav Physiol 17:223-232

> Forward RB Jr, Wellins CA (1989) Behavioral responses of a larval crustacean to hydrostatic pressure: Rhithropanopeus har-risii (Brachyura: Xanthidae). Mar Biol 101: $159-172$

Grasset O (2001) Calibration of the R ruby fluorescence lines in the pressure range $0-1 \mathrm{GPa}$ and the temperature range 250-300K. High Press Res 21:139-157

Gregg CJ, Stein FP, Morgan CK, Radosz M (1994) A variable volume optical pressure-volume-temperature cell for high-pressure cloud points, densities, and infrared spectra, applicable to supercritical-fluid solutions of polymers up to 2 Kbar. J Chem Eng Data 39:219-224

Gross M, Jaenicke R (1994) The influence of high hydrostatic pressure on structure, function and assembly of proteins and protein complexes. Eur J Biochem 221:617-630

Horikawa DD, Iwata K, Kawai K, Koseki S, Okuda T, Yamamoto K (2009) High hydrostatic pressure tolerance of four different anhydrobiotic animal species. Zoolog Sci 26: $238-242$

Kaye JZ, Baross JA (2004) Synchronous effects of temperature, hydrostatic pressure, and salinity on growth, phospholipid profiles, and protein patterns of four Halomonas species isolated from deep-sea hydrothermal-vent and sea surface environments. Appl Environ Microbiol 70: 6220-6229

Koyama S, Miwa T, Sato T, Aizawa M (2001) Optical chamber system designed for microscopic observation of living cells under extremely high hydrostatic pressure. Extremophiles 5:409-415

Lonsdale P (1977) Clustering of suspension-feeding macro- 
benthos near abyssal hydrothermal vents at oceanic spreading centers. Deep-Sea Res 24:857-863

Marsh AG, Mullineaux LS, Young CM, Manahan DT (2001) Larval dispersal potential of the tubeworm Riftia pachyptila at deep-sea hydrothermal vents. Nature 411:77-80

Oger PM, Daniel I, Picard A (2006) Development of a lowpressure diamond anvil cell and analytical tools to monitor microbial activities in situ under controlled $P$ and $T$. Biochim Biophys Acta Proteins Proteom 1764: 434-442

Partridge JC, White EM, Douglas RH (2006) The effect of elevated hydrostatic pressure on the spectral absorption of deep-sea fish visual pigments. J Exp Biol 209:314-319

Pradillon F, Gaill F (2007) Pressure and life: some biological strategies. Rev Environ Sci Biotechnol 6:181-195

Pradillon F, Shillito B, Chervin JC, Hamel G, Gaill F (2004) Pressure vessels for in vivo studies of deep-sea fauna. High Press Res 24:237-246

Raber EC, Dudley JA, Salerno M, Urayama P (2006) Capil-

Editorial responsibility: Hans Heinrich Janssen, Oldendorf/Luhe, Germany lary-based, high-pressure chamber for fluorescence microscopy imaging. Rev Sci Instrum 77:096106

Ross RM, Quetin LB (1985) The effect of pressure on the sinking rate of the embryos of the Antarctic krill, Euphausia superba. Deep-Sea Res 32:799-807

Sakiyama T, Ohwada K (1998) Effect of hydrostatic pressure on the growth of deep-sea bacterial communities. Proc NIPR Symp Polar Biol 11:1-7

Shillito B, Le Bris N, Gaill F, Rees JF, Zal F (2004) First access to live alvinellas. High Press Res 24:169-172

Yancey PH (2009). Deep-sea biology. http://people.whitman. edu/ yancey/deepsearesearch.html

Yoshiki T, Toda T, Yoshids T, Shimizu A (2006) A new hydrostatic pressure apparatus for studies of marine zooplankton. J Plankton Res 28:563-570

Yoshiki T, Yamanoha B, Kikuchi T, Shimizu A, Toda T (2008) Hydrostatic pressure-induced apoptosis on nauplii of Calanus sinicus. Mar Biol 156:97-106

Submitted: April 28, 2010; Accepted: October 18, 2010

Proofs received from author(s): December 3, 2010 